\title{
Estimates of residential floor vibration induced by sonic booms
}

Jacob Klos Acoustical Society of America May 23, 2016

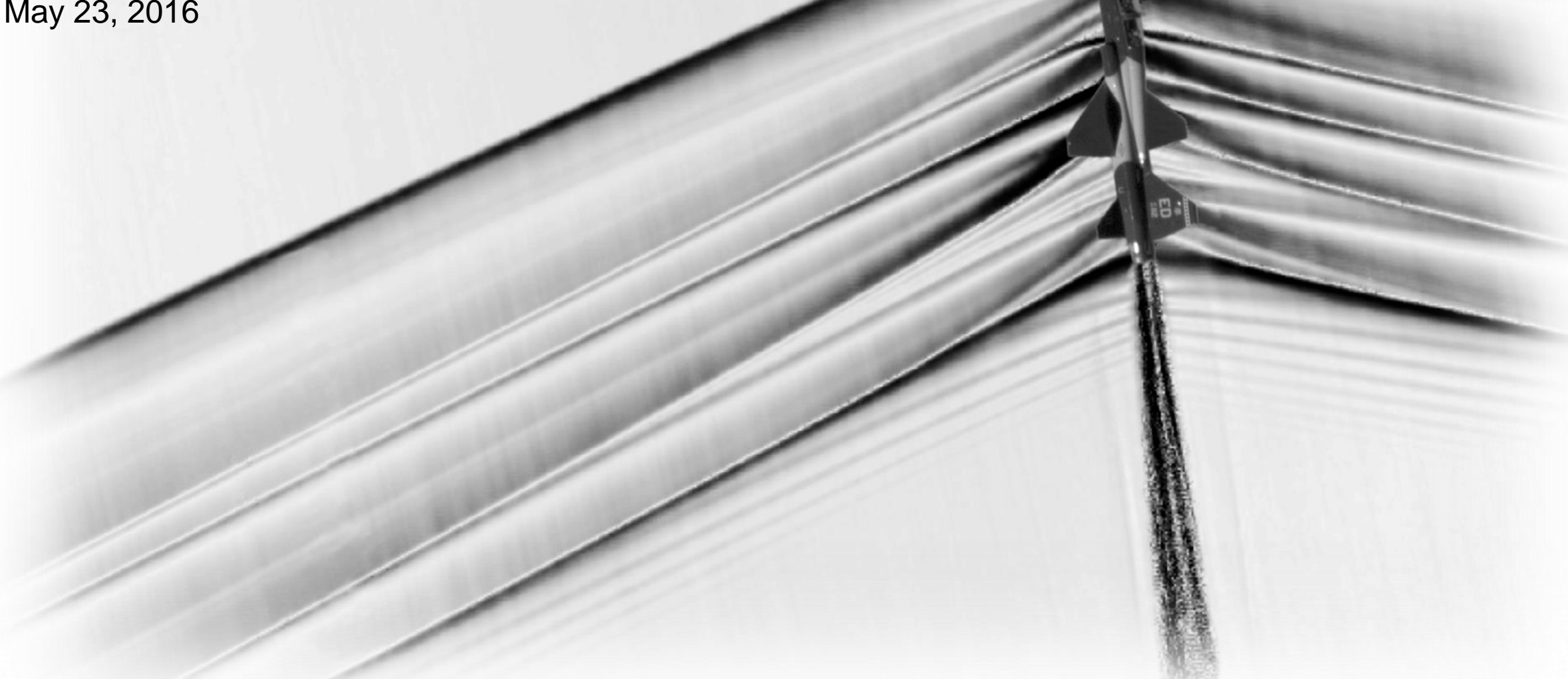

Image Source: http://www.nasa.gov/centers/armstrong/features/shock_and_awesome.html 


\section{Motivation and Outline}

- Large area exposed

- Study people's subjective reaction to anticipated indoor exposure

- Need estimates of vibration exposure in residential homes

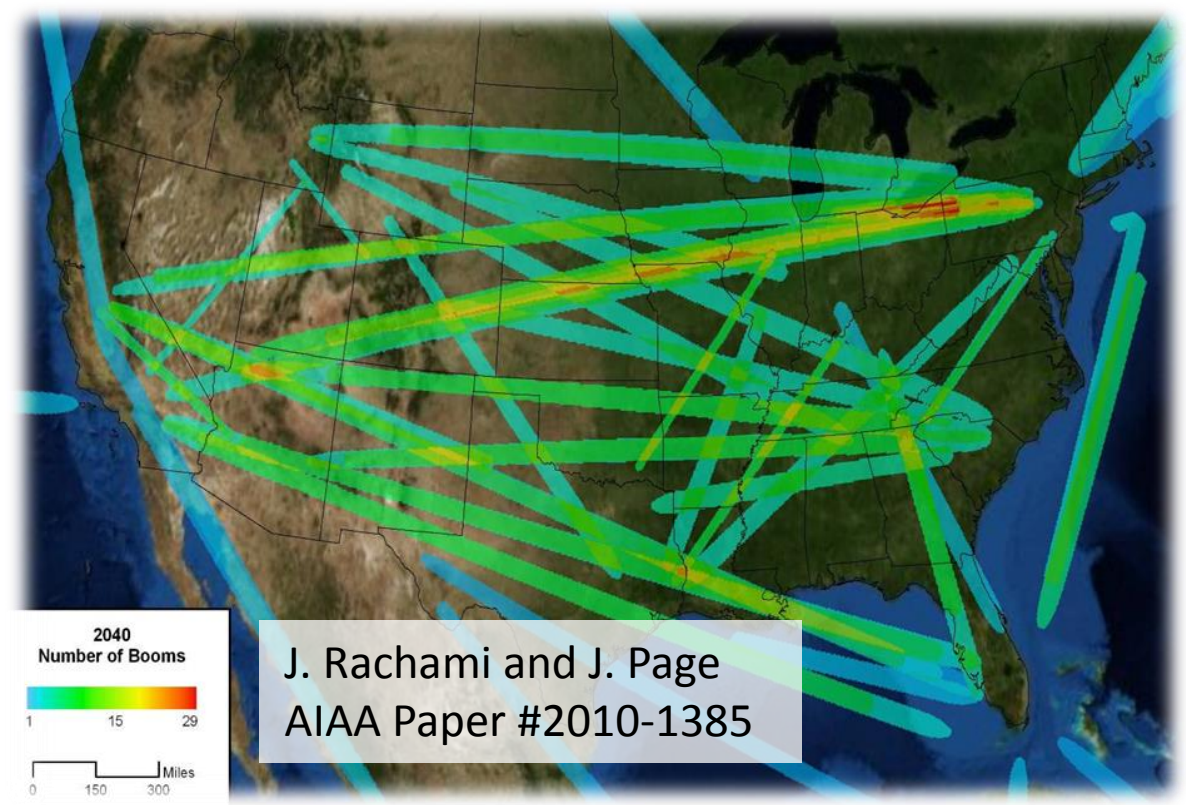

- Brief review of modeling approach

- Review a numerical design of experiment

- Illustrate histograms used to inform a psychoacoustic test

- Discuss comparison to experiments 


\section{Why Use Predictions}

- Define likelihood of experiencing a particular level

- Relevant experimental data is limited

- Model response to aircraft that don't yet exist

- Consider response quantities that are not in existing sonic boom literature 


\section{Modeling Approach}

- Developed at Virginia Tech (PI: Ricardo Burdisso)

- Exterior loading: edge diffraction toolbox ${ }^{1}$ (Peter Svensson)

- Structural response and interior acoustics: transient modal interaction model ${ }^{2}$

- Formulated in terms of uncoupled Eigen solutions

- Coupled indoor vibro-acoustic response

- Structural envelope: Eigen solution of an in vacuo orthotropic plate ${ }^{3}$ finite element model

- Output is time domain interior pressure and/or structural vibration

${ }^{1}$ Edge Diffraction Toolbox: http://www.iet.ntnu.no/ svensson/software/

${ }^{2}$ Remillieux, et. al., Transmission of sonic booms into a rectangular room with a plaster-wood wall using a modal - interaction model, J. Sound and Vibration, 327 (2009) pp 529-556.

${ }^{3}$ Harne, et. al., Structural-acoustic aspects in the modeling of sandwich structures and computation of equivalent elasticity parameters, Thin-Walled Structures, 56 (2012) pp 1-8. 


\section{Numerical Design of Experiment}

- Ten factors were analyzed

- An ensemble of 5832 houses

- Houses had a wood framed floor with crawl space

- Only considered limp siding material (e.g. no brick or stucco in the present analysis)

- Windows were closed

- Doors were not included in the structural model 


\section{Factors Influencing Exterior Loading}

- Incident waveform: aircraft configurations

7 low boom aircraft concepts 2 conventional military aircraft

- Source incidence azimuthal angle

12 equally spaced angles (30 degree increment)

- Source incidence elevation angle

30 degrees

45 degrees 


\section{Factors Influencing Physical Properties}

- Different floor plans

Four generic floor plans Edwards ranch Edwards two story

- Exterior wall construction

- Floor joist depth

- Window construction

- Structural damping

- Acoustic damping

- Structural stiffness to mass ratio
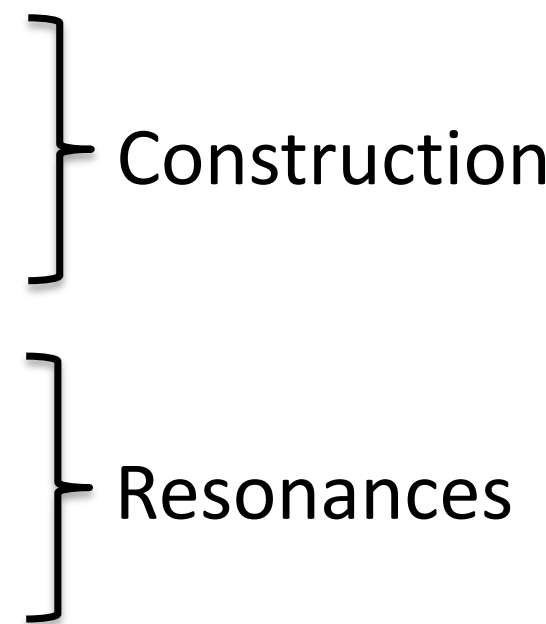

- Full factorial analysis:

- 1,259,712 house-source combinations

- Each with about 100 virtual accelerometers on the floor

- Analysis took 2 weeks to complete 

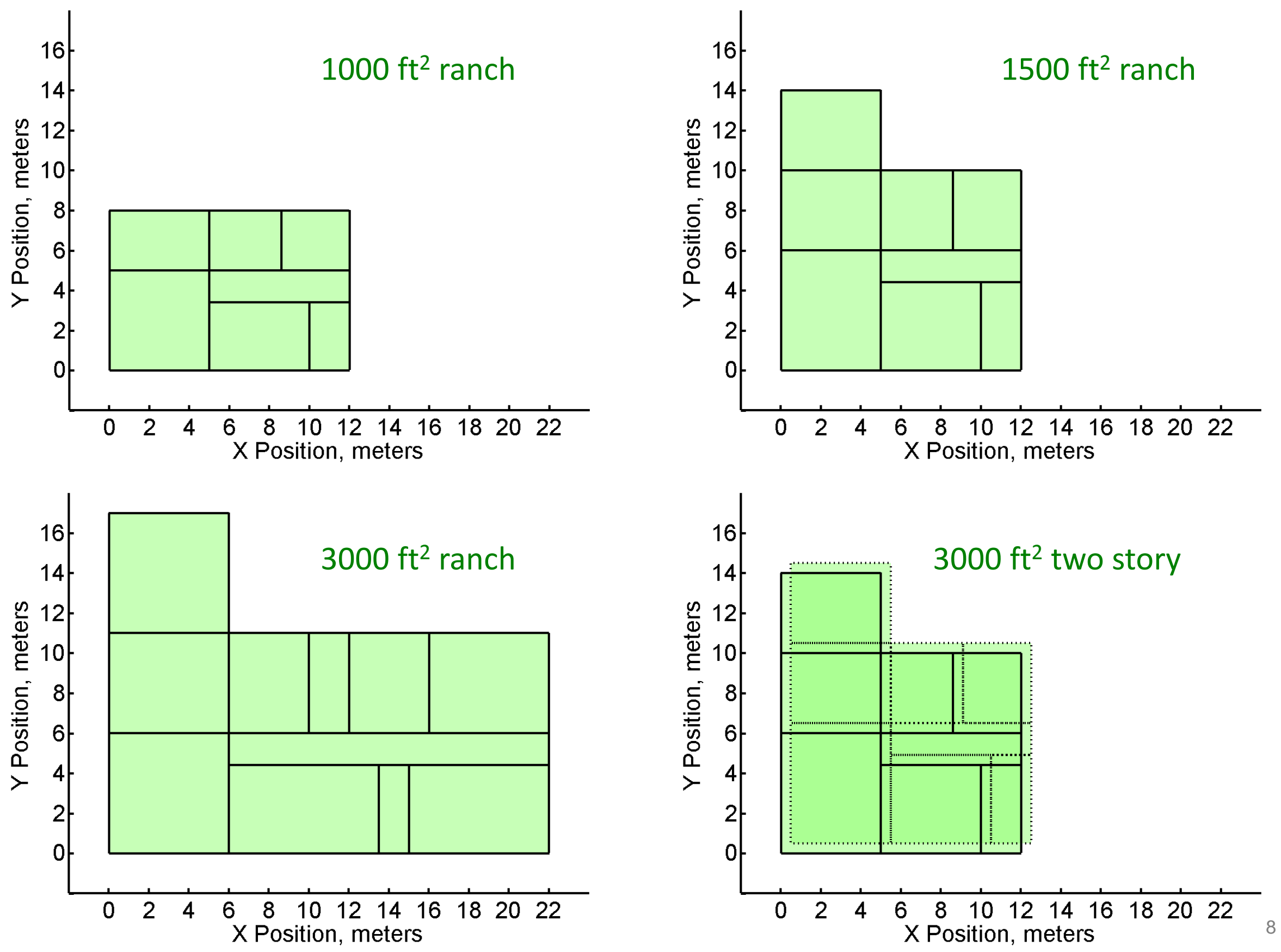


\section{Example Vibration Distributions}

- Fixed outdoor loudness level of $80 \mathrm{~dB}$ [perceived level]

- Binned the peak floor acceleration

- Different low boom aircraft concepts
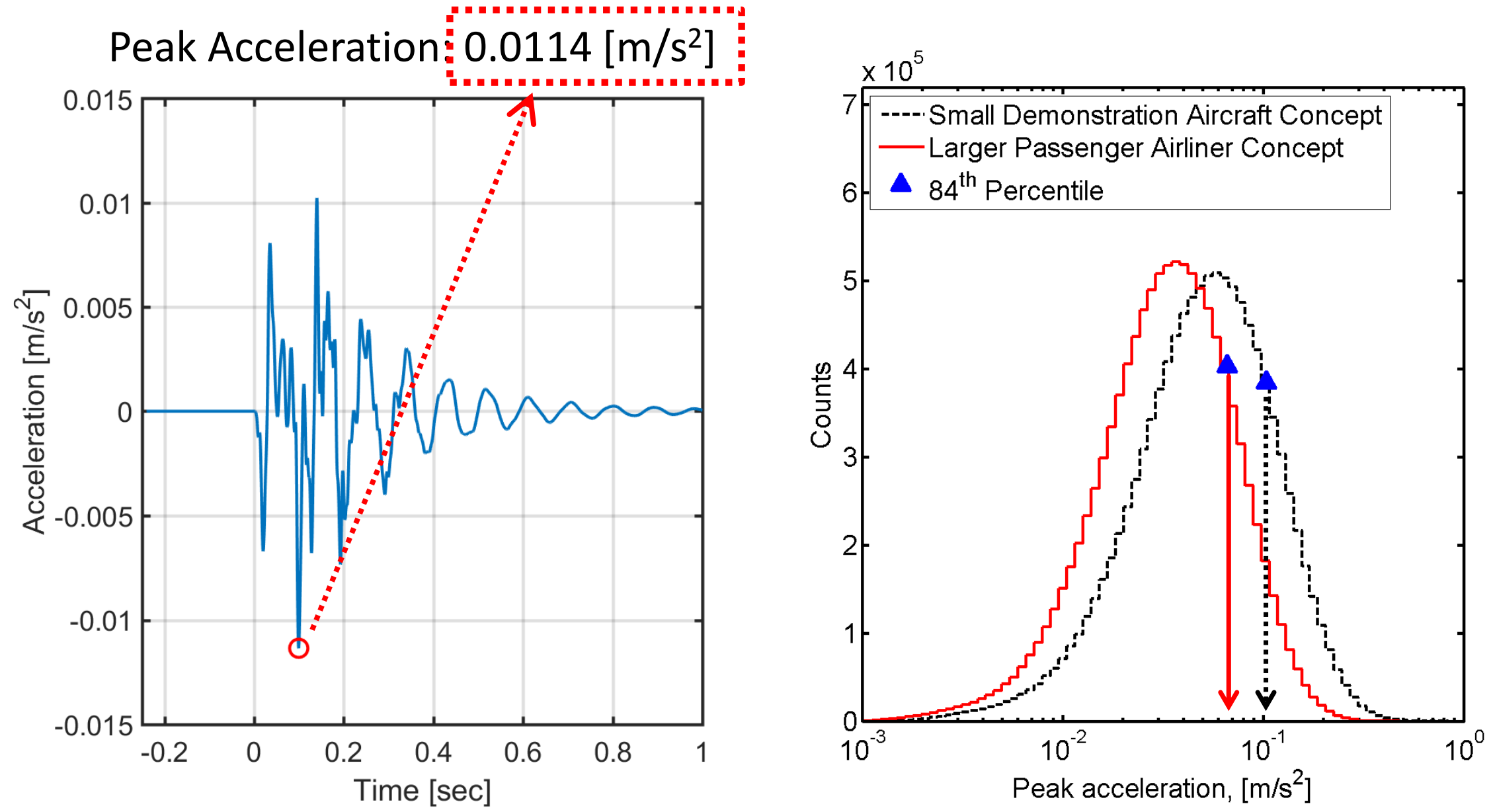


\section{$\mathrm{W}_{\mathrm{k}}$ Weighted Peak Acceleration}

- ISO 2631 parts 1 and 2 - whole body vibration

- $W_{k}$-weighting filter (Psycho-physical metric)

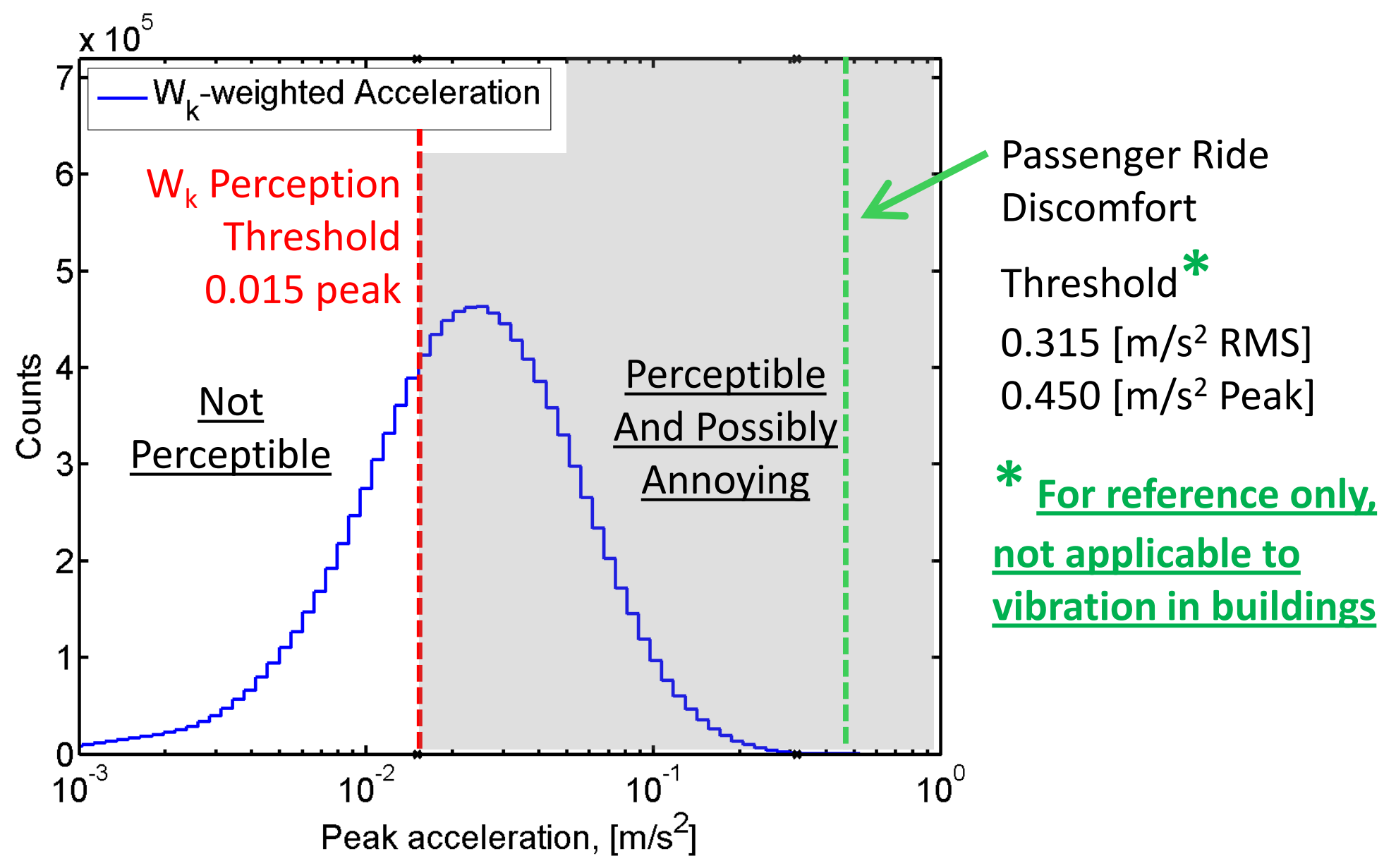




\section{Edwards (1966) Test Data}

- USAF and NASA study in 1966 on two purpose built homes

- Homes had wood framed floors with crawl spaces

- N-wave excitations from a B-58 and a F-104 military aircraft

- Analysis by Sutherland and Czech (NASA CR \#189584, 1992)

Transducer \# 311 (Wall Mounted Accel)

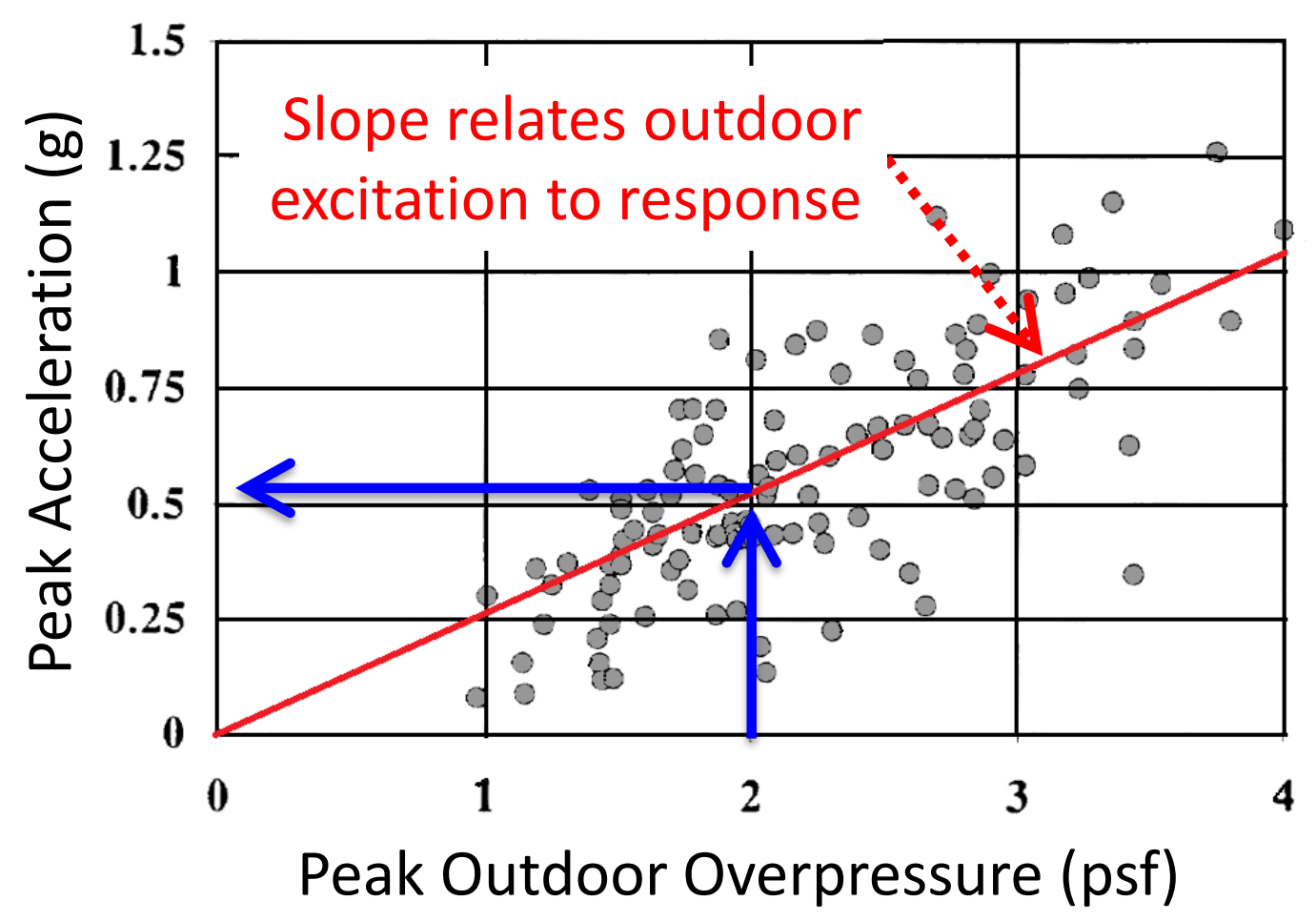

Slopes for floor accels [g/psf]

\begin{tabular}{|c|c|c|c|}
\hline & \multicolumn{2}{|c|}{ Aircraft Type } \\
\hline & & B-58 & F-104 \\
\hline \multirow{3}{*}{ 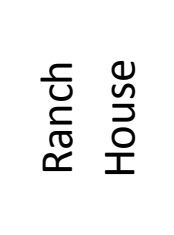 } & Floor Accel \#1 & 0.069 & 0.090 \\
\hline & Floor Accel \#2 & 0.043 & 0.062 \\
\hline & Floor Accel \#3 & 0.052 & 0.058 \\
\hline \multirow{2}{*}{ 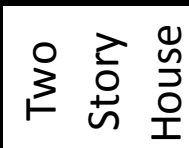 } & Floor Accel \#1 & 0.048 & 0.049 \\
\hline & Floor Accel \#2 & 0.041 & 0.060 \\
\hline
\end{tabular}




\section{Predicted Vs. Measured Floor Vibration}

- Modeled response to a 2 psf N-wave from two military aircraft

Edwards Two Story House

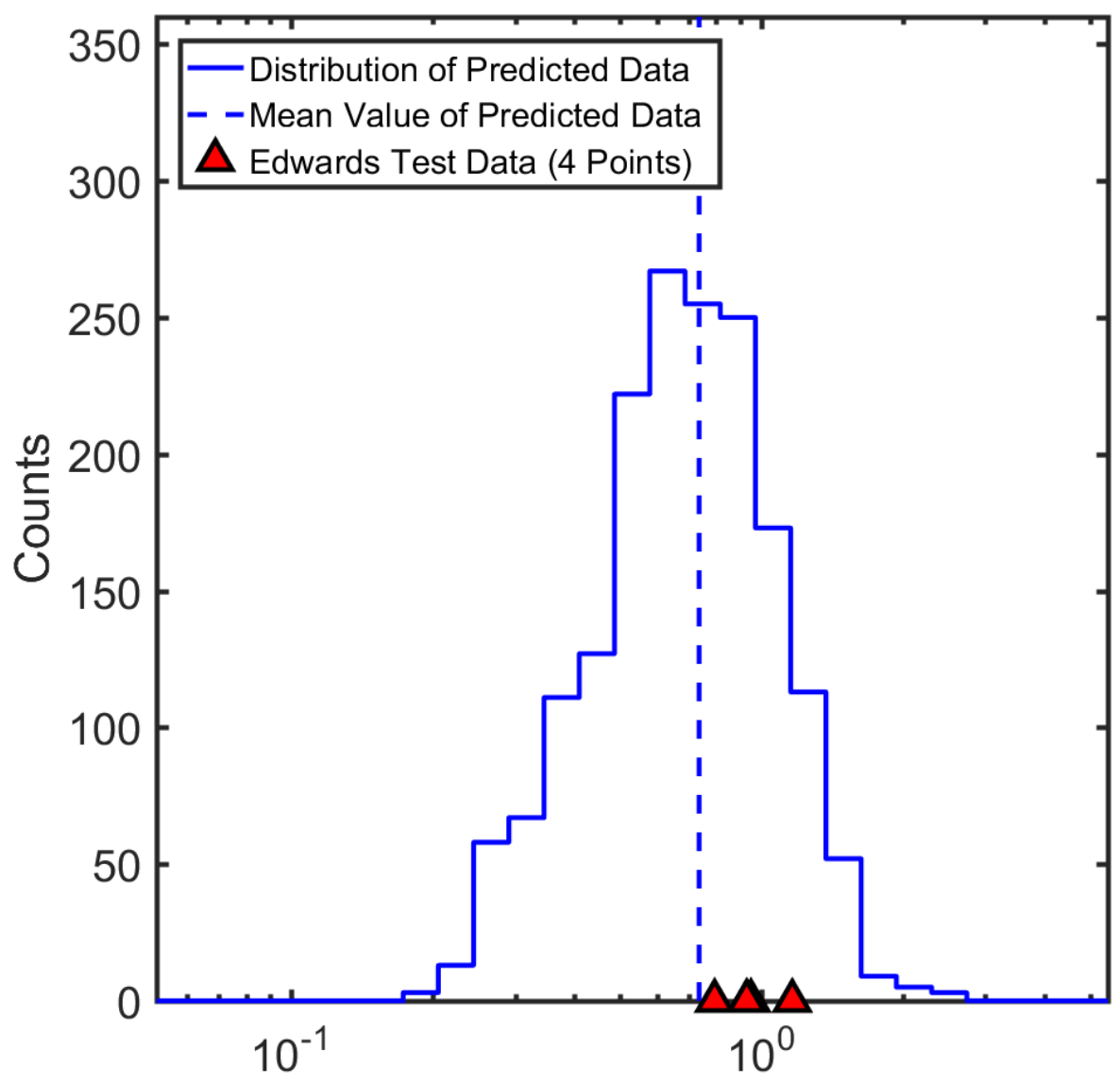

Peak un-weighted acceleration, $\left[\mathrm{m} / \mathrm{s}^{2}\right.$ ]
Edwards Ranch House

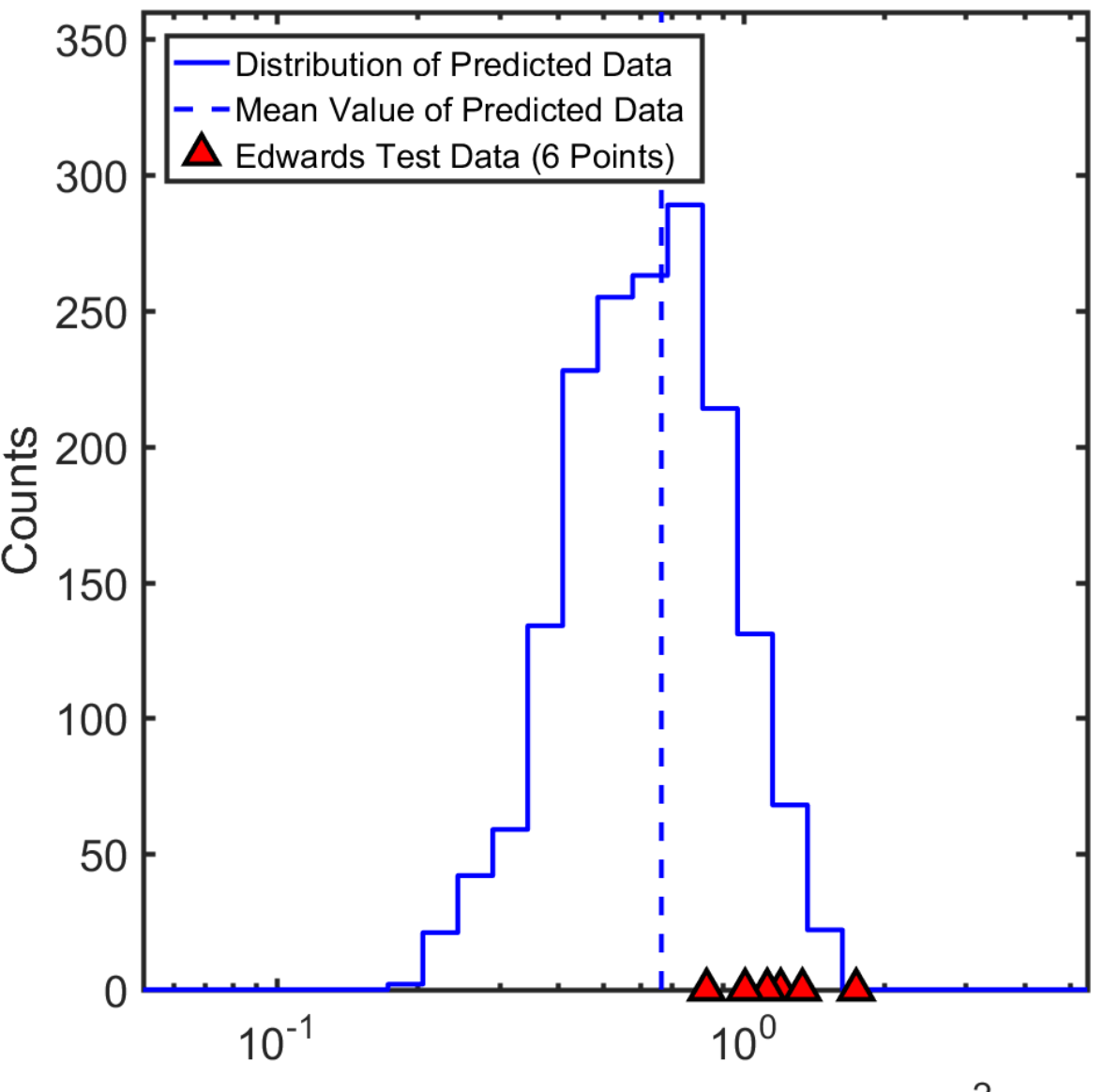

Peak un-weighted acceleration, $\left[\mathrm{m} / \mathrm{s}^{2}\right]$ 


\section{Summary}

- Estimated vibration exposure in homes for a variety of aircraft

$>$ Low boom exposure ranges from imperceptible to perceptible

$>$ Need to study how subjective annoyance varies with anticipated range in levels

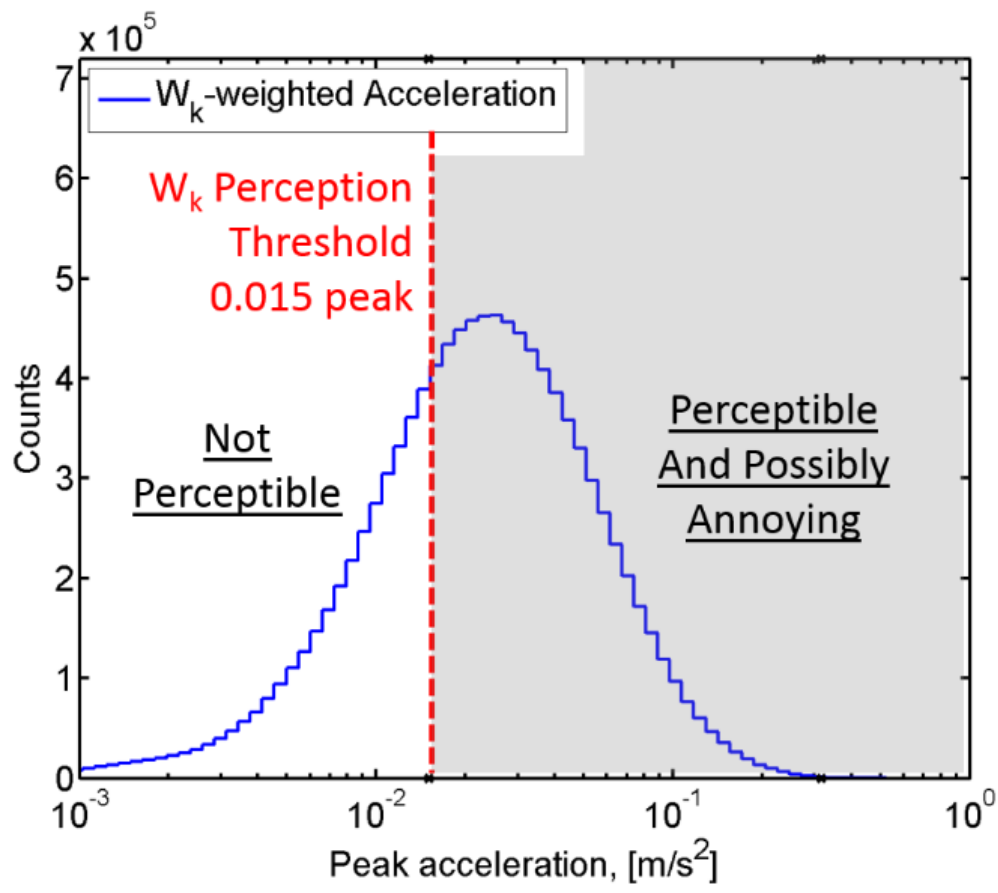

- Favorable comparison of predictions to test for conventional military aircraft

- Floor vibration is a conservative exposure estimate 
Backup Slides 


\section{Edwards Test Houses (1966, Ranch House)}

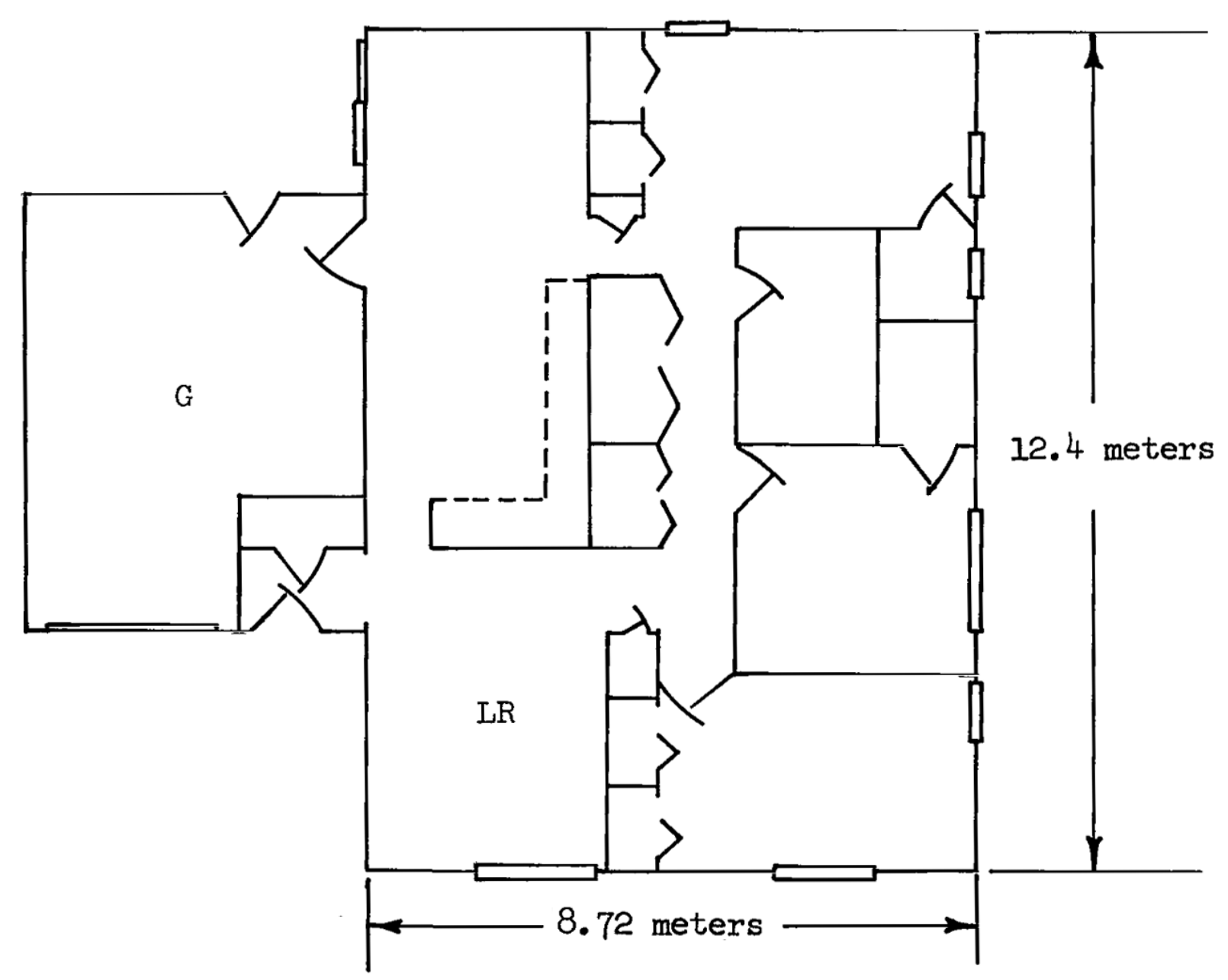




\section{Edwards Test Houses (1966, Two Story House)}
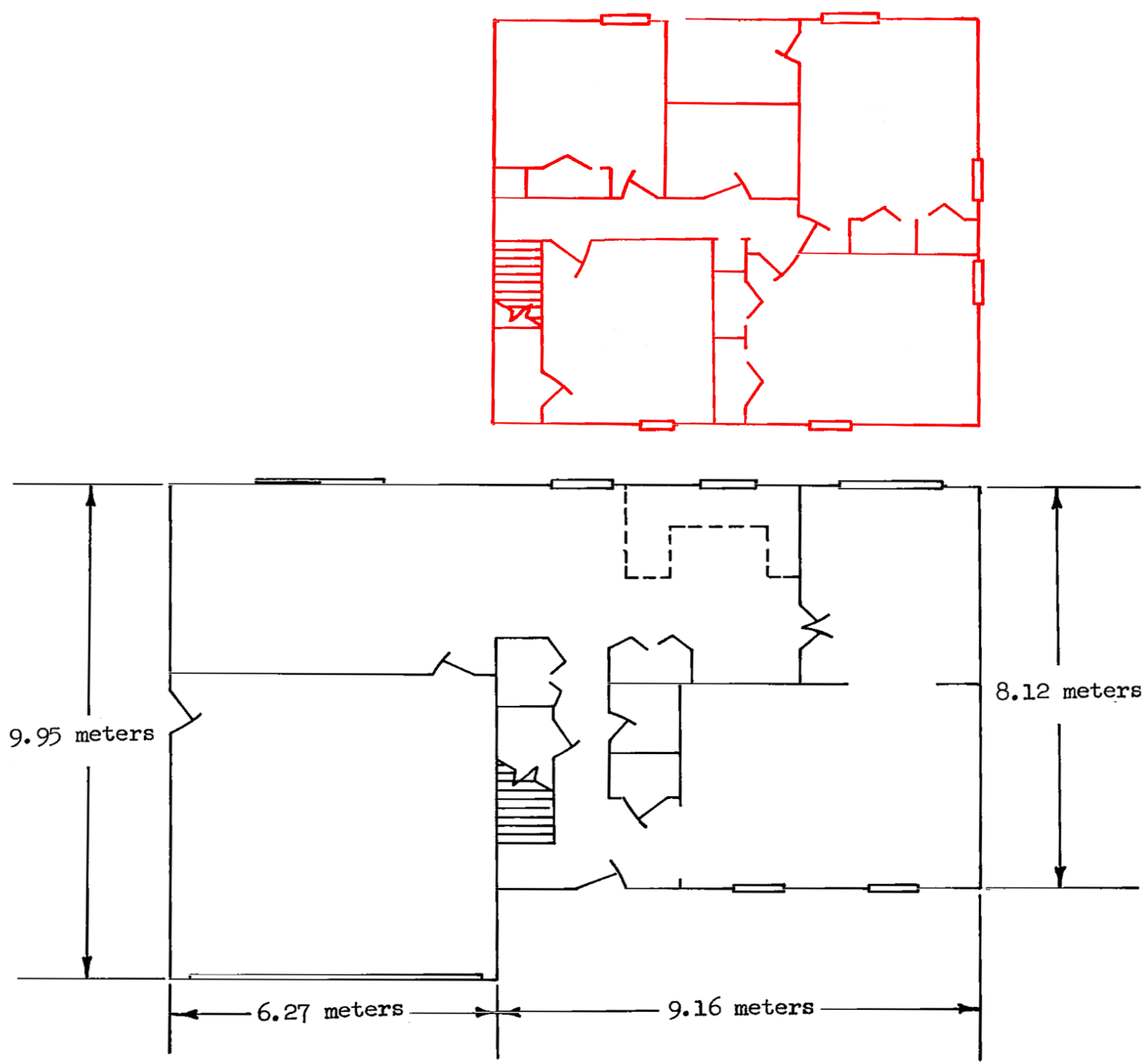


\section{Experimental Validation: Interior Pressure}

- Comparisons between measurements in the IER and predictions using VA Tech code were made

- Microphone time histories and spectra were compared

- Typical microphone response is shown to the right

- Loudness level inside the IER

\begin{tabular}{|c|c|c|}
\hline \multirow{2}{*}{ Mic \# } & \multicolumn{2}{|c|}{ Perceived Level $(\boldsymbol{d B})$} \\
\cline { 2 - 3 } & Measured & Predicted \\
\hline 1 & 73.8 & 74.2 \\
2 & 75.3 & 76.1 \\
3 & 75.9 & 75.7 \\
4 & 73.5 & 72.1 \\
5 & 73.0 & 73.7 \\
\hline
\end{tabular}

- Good agreement between experiment and VARS was obtained
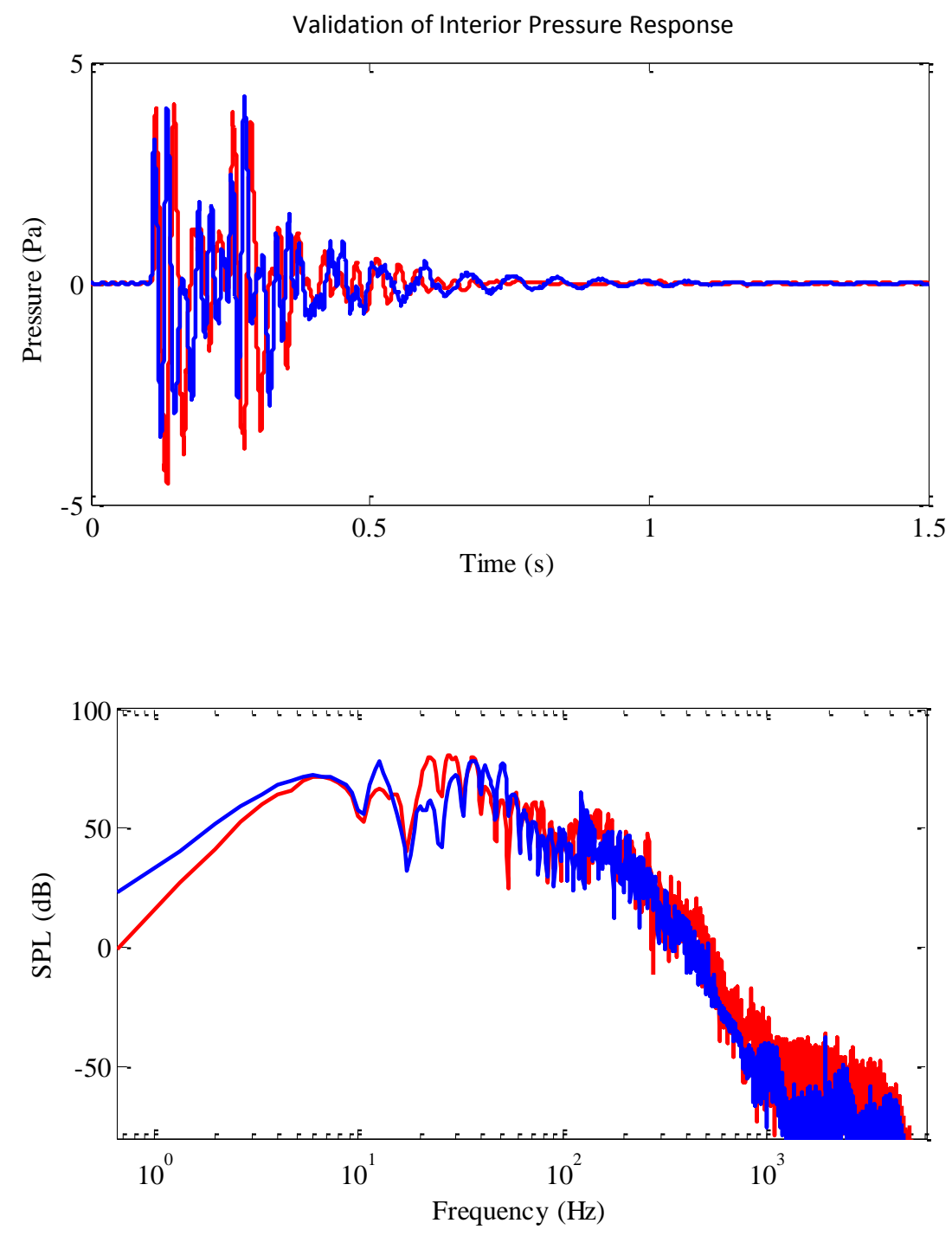


\section{Measured vs. predicted structural mode shapes (pink noise excitation, low frequency)}

Window fundamental

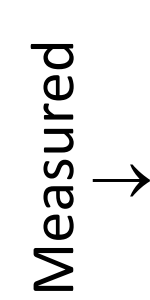

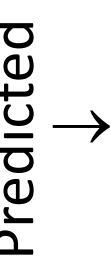
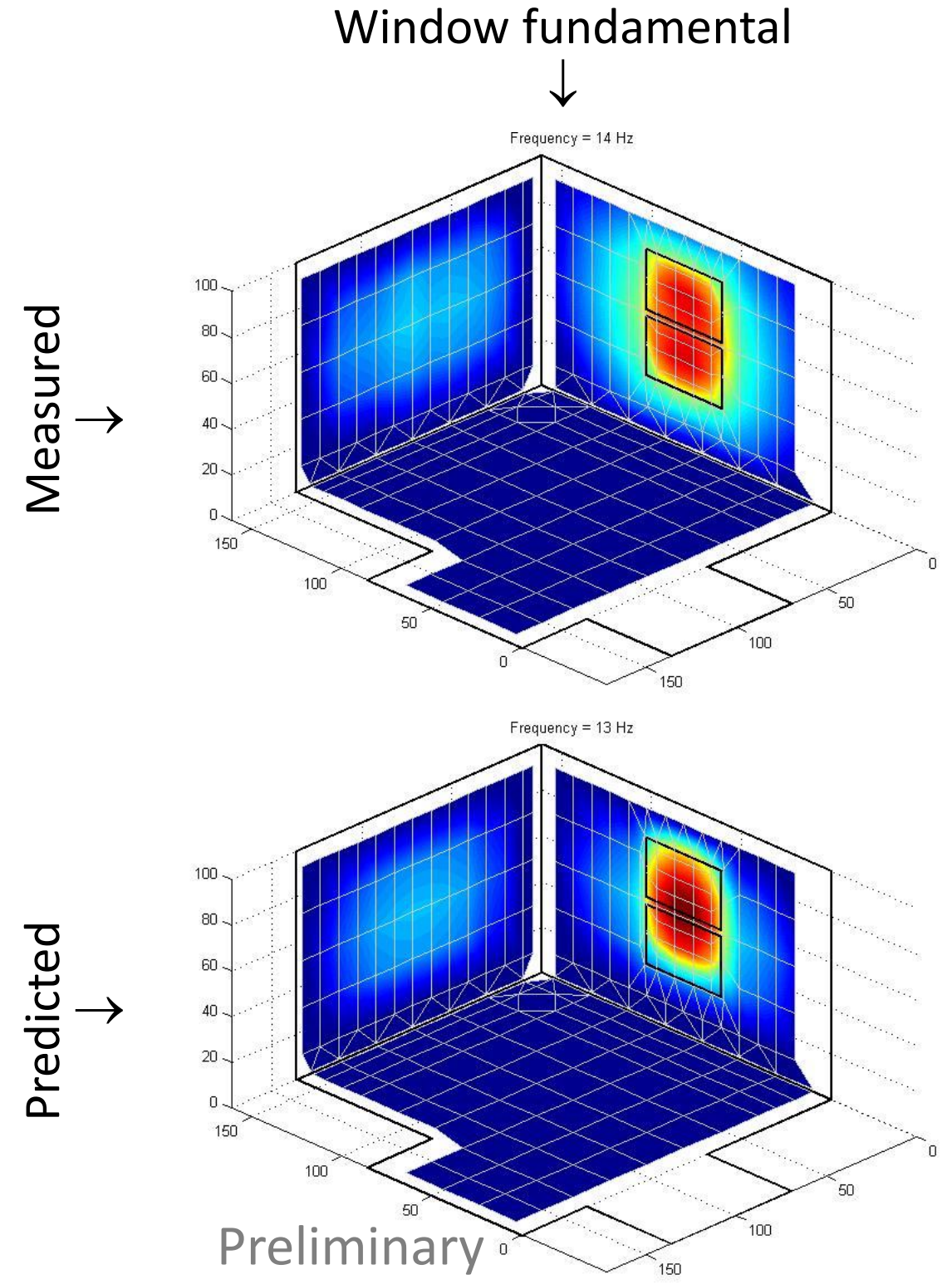

Wall fundamental $\downarrow$
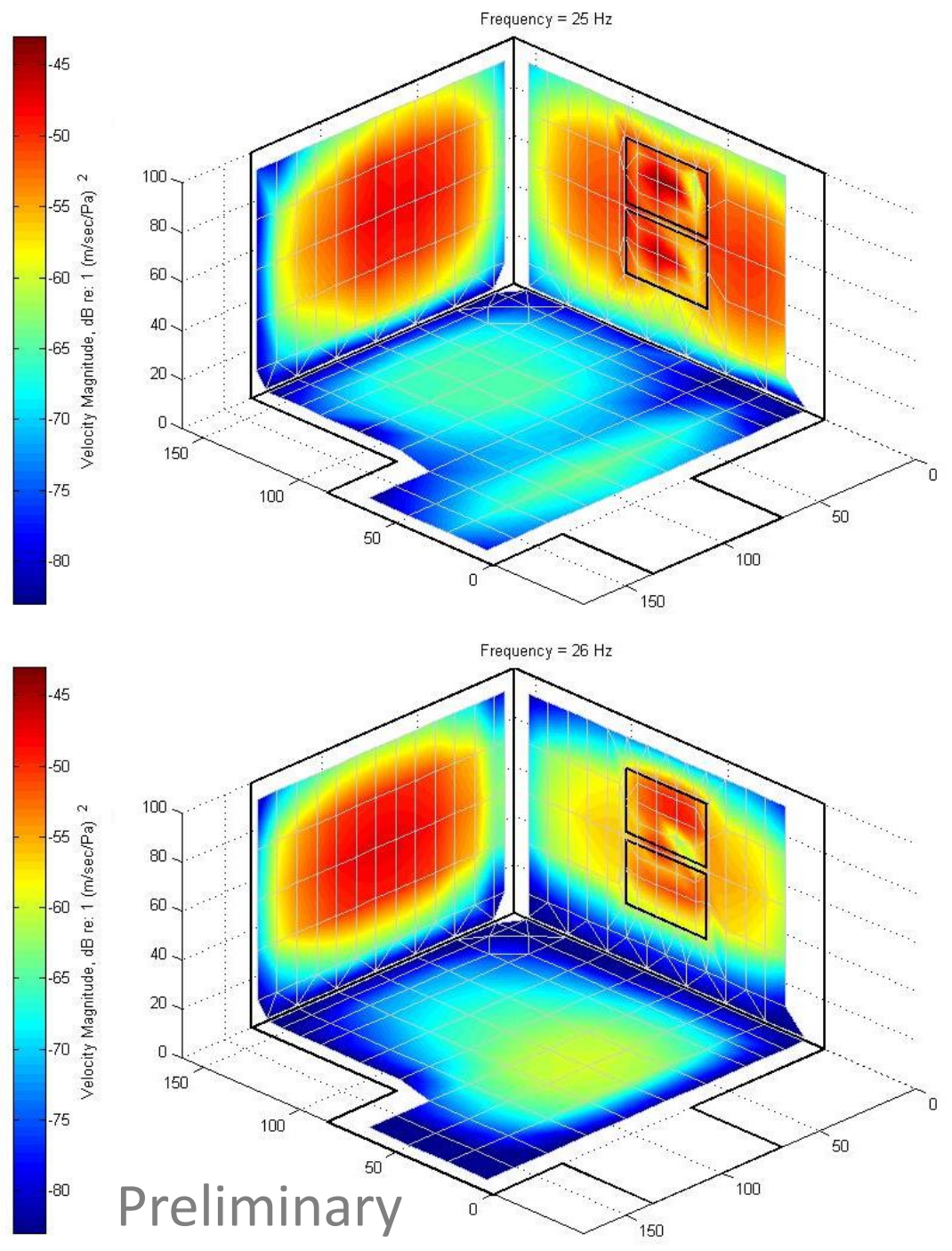

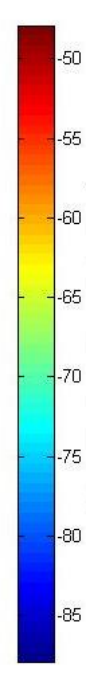




\section{Edge Diffraction vs. Boundary Element}

- Edge diffraction toolbox

- Written by Peter Svensson at the Norwegian University of Science and Technology

- Incorporated into VARS to predict exterior loading

- Compared frequency domain BEM to edge diffraction toolbox predictions

- Spatial distribution of sound pressure level at $60 \mathrm{~Hz}$ is shown, incident side

- Good agreement comparing all three methods

BEM, Plane Wave Source

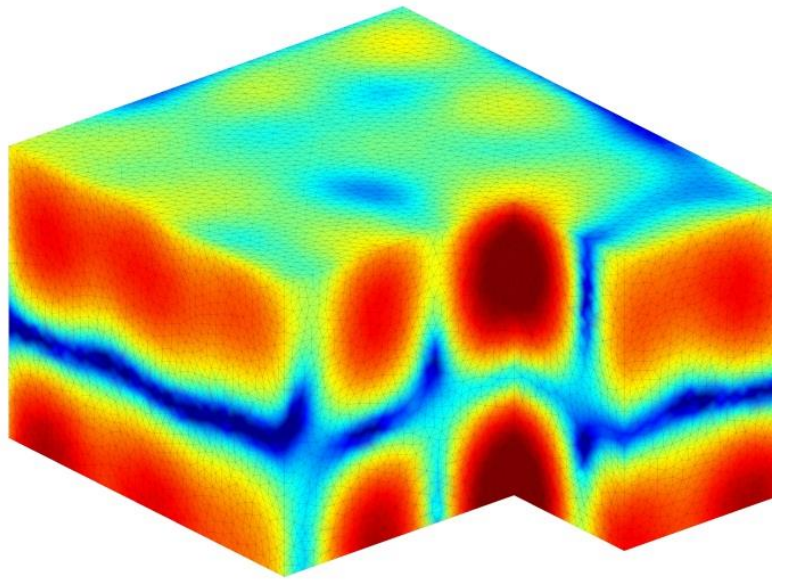

80 ${ }^{85} \stackrel{90}{90} \stackrel{95}{95}{ }^{100}$
BEM, Distant Point Source
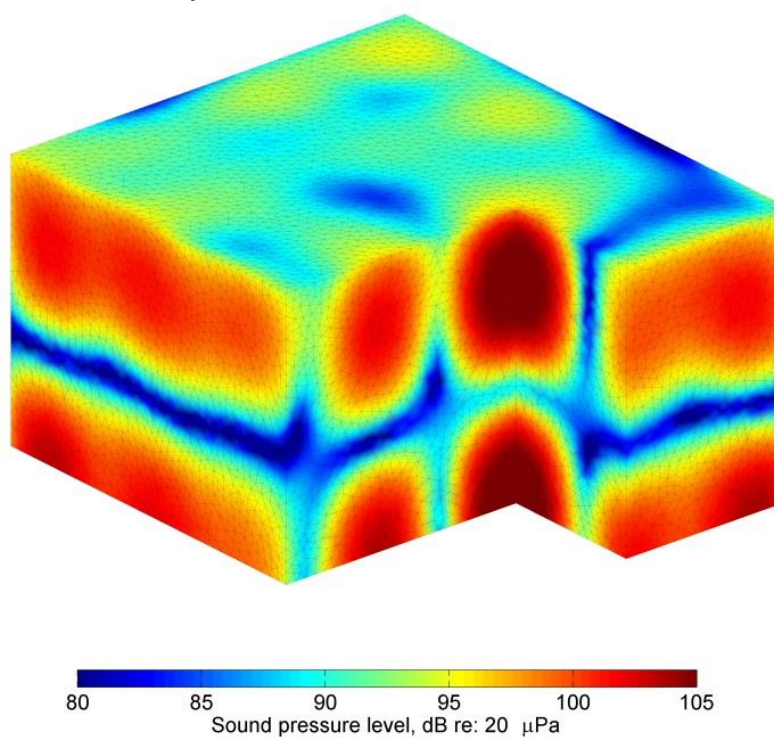

VARS, Distant Point Source
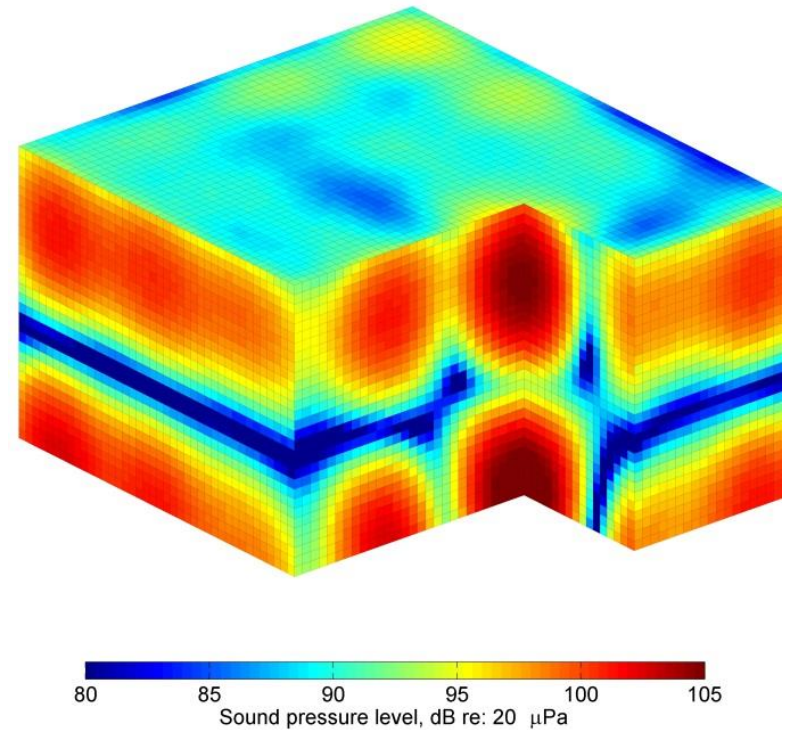

Nominal level on the ground in absence of the building is $94 d B$ (light green) 


\section{Edge Diffraction vs. Boundary Element $(60 \mathrm{~Hz})$ NASA}

- Spatial distribution of sound pressure level at $60 \mathrm{~Hz}$ is shown

- Shadow side of the building

- Nominal level on the ground in absence of the building is $94 \mathrm{~dB}$ (light green)

- Good agreement in level comparing all three methods

- VARS lack some fine detail due to limited diffraction order ( $2^{\text {nd }}$ order was used)

BEM, Plane Wave Source

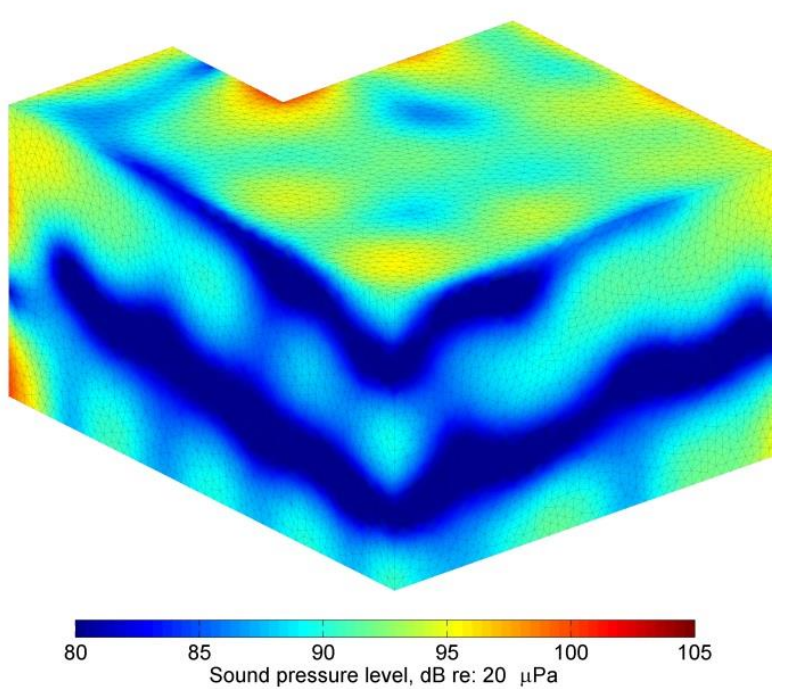

BEM, Distant Point Source

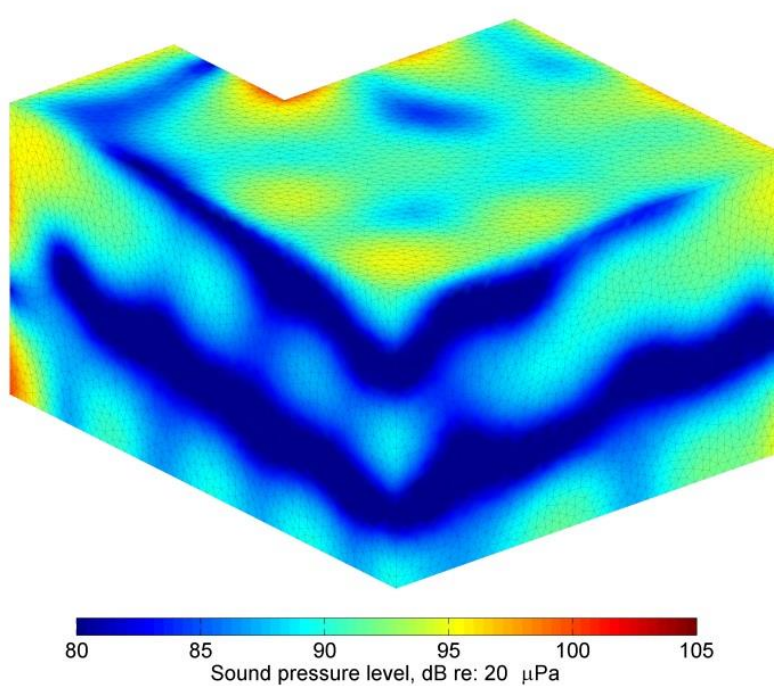

VARS, Distant Point Source

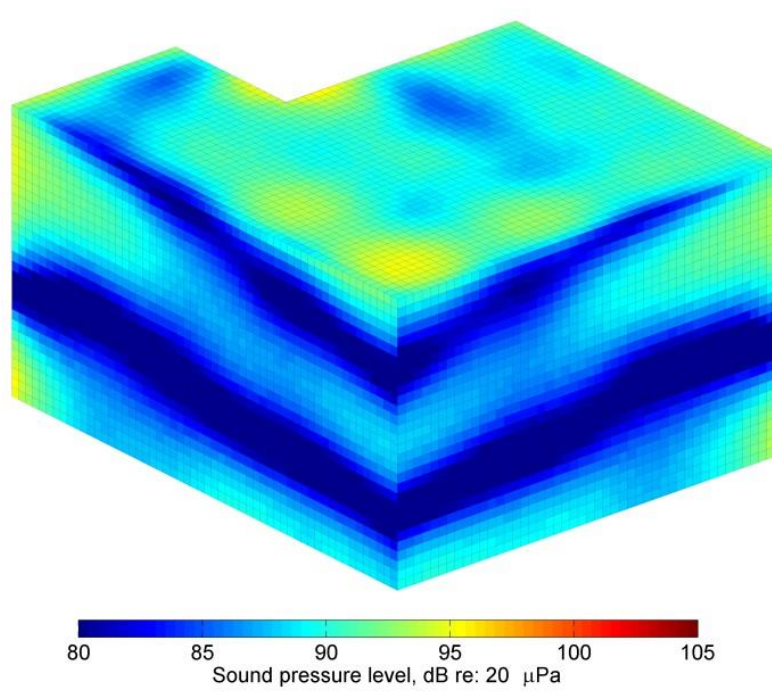

